\title{
Nuestro teatro en el Cervantes on line Puestas de la emergencia que se convierten en emergentes
}

\section{Adriana Libonati}

Durante estos tiempos de zozobra, temor e incertidumbre surge esta feliz idea para generar contenidos y colaborar con el sostenimiento material de artistas y técnicos. Hacía mucha falta; el cierre de los teatros por la pandemia hizo sufrir a los espectadores y a los teatristas. La idea se implementa mediante un concurso de dramaturgia integrado por el Comité de preselección, constituido por: Ana Alvarado, Andrea Garrote y Juan Parodi (CABA), Sebastián Fanello (Neuquén), Romina Mazzadi Arro (Santa Fe) y Ariel Dávila (Córdoba). Las obras luego serían revisadas para la selección final por un Jurado constituido por Romina Chepe, Mónica J. Paixao y por las autoridades del propio Teatro, Rubén D'Audia y Sebastián Blutrach. Se eligieron veintiún obras para ser presentadas con distintos elencos y direcciones. Fueron filmadas en la sala María Guerrero del TNC para su posterior presentación en el Cervantes Online. Es importante señalar que las obras, luego de estrenadas permanecen en la plataforma de Youtube, continuando y multiplicando sus sentidos por los monitores del mundo.

Todavía el ciclo está transcurriendo y en la imposibilidad de hacer una nota que las abarque a todas, se seleccionaron algunas que muestran los rasgos convergentes y divergentes de esta simbiosis entre teatro y cine, tomando en consideración que hacer teatro en tiempos de Covid-19 presenta una serie de dificultades para su realización: ensayar con barbijo, mantener distancias físicas, depender de las formas digitales para plasmar las puestas y sobre todo, la ausencia física del público que afecta tanto a actores como a espectadores. Es importante destacar esta hermandad existente entre el teatro y las artes tecnodigitales, que en otros tiempos pudieron considerarse opuestas pero que en estos días podemos verlas como colaboradoras.

\section{Lo sutil del desamor}

Parodia de la función del dramaturgo en su cariz de homenaje y autorreferencialidad. Una pareja que para resolver situaciones alternan sus desempeños actanciales como ayudantes y oponentes de sus deseos. Los "personajes creados" completan el elenco y van tomando las acciones que se diseñan para ellos, aunque con el correr de los minutos van adquiriendo las características que los autores quieren disimular sobre ellos mismos, hasta llegar a mimetismos especulares. Hay música de piano en vivo y una marcada referencia a los espectadores a quienes "mirando a cámara" se los interpela. 


\begin{abstract}
Al hueso!!
Dos hermanas que viven en la vieja casa de la decadente burguesía porteña reciben la visión fantasmagórica de Juan Domingo Perón. Una de ellas, con vestimenta etérea y que mantiene un lenguaje muy poético con intertextos de los discursos de Eva Perón, lo recibe con alegría y quiere vivir un sueño. La otra, vestida con ropa de calle, insiste en descubrir los acontecimientos que llevaron al deterioro de la casa. Se intuye que la respuesta está en una pequeña habitación cuya llave se ha perdido. Esa llave es entregada por el fantasma. Una vez abierta, los testimonios del horror aparecen. El sueño continúa.
\end{abstract}

\title{
Civilización
}

La obra comienza con música de bombos en la pampa argentina de la época del virreinato, en la noche del incendio del teatro de la Ranchería, en 1792. Dos hermanas, de la acriollada población orgullosas de su estirpe española están perdidas y hablan de su medio hermana mestiza, maltratada, envidiada, odiada y a la que creen muerta. El cuento de Cenicienta maltratada por las hermanastras revolotea entre los matorrales. Un oficial y un soldado de las fuerzas realistas completan el elenco, que se mueve en un espacio donde se cruzan lo fantástico con lo poético con evidente intención histórica. Los parlamentos son muy cuidados apareciendo referencias en clave a una cierta arte poética y a intertextos de Lope de Vega. Las actuaciones son teatralistas y crecen en intensidad, cuando entra en escena la hermana bastarda que se creía muerta. Este recurso de inclusión de un quinto personaje, está creciendo en las representaciones contemporáneas. Hay menciones importantes a la peste de Buenos Aires, con lo que el relato adquiere cotidianeidad y en el final existe un deseo expreso de que la peste termine.

\section{Puzzle}

Comienza con una luz violeta que baña el banco de una plaza. Se ve a dos hombres con valija y vestidos con colores simétricos pero con las prendas invertidas (corbata azul, chaqueta verde) (chaqueta azul, corbata verde), que deben encontrarse en una fecha y hora precisas, aunque no recuerdan su propio nombre ni porque deben encontrarse. Cada uno de ellos tiene los recuerdos del otro pero olvidó los propios. Hay un intercambio en las rememoraciones que adquieren connotaciones de Sujeto/Objeto, mediante la construcción de un sistema de personajes que va uniendo los fragmentos de recuerdos, negados o admitidos por los protagonistas. Semánticamente, se trata de la búsqueda de la verdad y de la memoria por medio de un teatro que ejercita la acción en espejo y que mediante una simetría axial de las buenas actuaciones, vistas por los primeros planos que permite la cámara, va adquiriendo un perfume becketiano.

\section{El rumor de las palomas}

El típico triángulo está formado por una pareja y un tercero imaginado, que es el desafío y la resistencia. La actuación es de resolución plástica. Se trata de un sistema de tensiones que no prioriza un aspecto sobre el otro. Tiene música en vivo. Se enmarca en un bicromatismo escénico en blanco y negro. Las actuaciones fuera del espacio acotado basculan entre la búsqueda de la libertad y la osadía, con desempeños mucho más activos. Dentro de ese dispositivo, los actores mantienen una contención emocional; cuando están fuera de él, pueden expresar sus emociones. El tercero en ese triángulo, es la intemperie, lo que está afuera: el miedo, el peligro, el vértigo y por enlace metafórico, la pandemia. 


\section{El derecho de las cosas}

Dos muy buenos intérpretes con monólogos muy poéticos, nos muestran un espacio escénico que podría convertirse en la representación de otro, mucho más extenso y global: Jean Paul, en su sillón bebiendo whisky y La Chica, salvando obstáculos: desde una barrera de mesas, mesadas y alacenas destruidas, tomando mate. Jean Paul le muestra a ella su botella vacía. La primera línea de interpretación es referenciar la puesta, en la "oposición/complementación entre Centro y Periferia". Desde un segundo nivel semántico se inclina el sentido hacia la "decadencia de los patriarcados" y en una tercera clave de lectura, se permite al espectador imaginar que está participando en la justicia poética al feminismo y su lucha. Durante el desarrollo de las secuencias se mantiene el discurso poético pero con menos metáforas que en la presencia espacial, y entonces aumenta el sentido crítico de la obra. Muy interesante propuesta.

\section{Camarín 19}

Se presenta la escena con el visor de una cámara. Las dos actrices se encuentran y van delineando acciones del espacio y su contexto. Actuarse a ellas mismas, otorga altos niveles de autorreferencialidad, tanto a quienes lo hacen como a quienes lo contemplan. Maquillarse, probarse diferentes ropajes o estrategias escénicas de caracterización o modificación del cuerpo, manteniendo buenos desempeños, siempre resulta interesante. Si a eso le sumamos la reflexión escénica sobre el teatro en los tiempos del covid 19, mucho más. Se cortan las luces, hay sonidos estridentes y amenazantes, la música se convierte en ruido, y tienen la certeza de que las están espiando continuamente. Los miedos se esconden entre los objetos que antes estaban para el servicio de ese camarín. ¿Acaso alguien puede decir que no sintió miedo al enfrentarse a los ojos misteriosos que miran desde lejos a través de una lente? Finalmente, confortándose mutuamente, ambas se animan y salen al escenario.

Si bien las obras analizadas podrían encuadrarse en lo que Hans-Thies Lehmann denomina "teatro posdramático", parodias de las autorías, condición de autorreferencialidad, mezclas o variantes de géneros, reflexión histórica crítica, etc., hay que reconocer que en estas puestas signadas por las diferentes facetas de la crisis de la pandemia, está surgiendo una mutación o una subespecie del teatro posdramático. La cantidad de elementos que se mencionan permitirían catalogar a este ciclo como de "Teatro Intrapandémico".

En tal sentido, las puestas poseen mezclas estéticas en lo que hace a estilos, formas de actuación, parlamentos y la incorporación de lo cinematográfico, que ocupa el lugar de la elección óptica espectatorial del teatro tradicional, que es reemplazada por los distintos encuadres de la cámara. Puede verificarse que casi todas poseen una corta duración que varía de los treinta a los sesenta minutos y además, tienen finales abruptos o sorpresivos, quizás siguiendo una lógica que plantearía que aún no se sabe cuándo terminará la pandemia. 


\section{Q Bibliografía}

» Lehmann, H. T. (2002). El teatro posdramático. París: L’Arche.

\section{Fichas técnicas}

Lo sutil del desamor: de Anahí Ribeyro. Direc. Paula Marull. Intérpretes: Héctor Díaz, Malena Fijó, María Marull, Marcelo Subiotto.

Al hueso!! De Santiago Dejesus. Direc. Pompeyo Audivert. Intérpretes: Julieta Carrera, Claudio Da Passano, Malena Solda.

Civilización: de Mariano Saba. Direc. Lorena Vega. Intérpretes: Julieta Brito, Andrea Nussembaum, María Inés Sancerni, Mariano Sayavedra, Gonzalo Urtizberea.

Puzzle: de Sergio Omar Lopardo. Direc. Santiago Doria. Intérpretes: Osmar Nuñez, Jorge Suárez.

El rumor de las palomas: de Mario Costello. Direc. Lorena Romanin. Intérpretes: Vanesa González, Juan Tupac Soler

El derecho de las cosas: de Guillermo Arengo. Direc. Analia Couceyro. Intérpretes: Daniel Fanego, Camila Santini

Camarín 19: de Vera Czemerinski. Direc. Alejandra Flechner. Intérpretes: Noralih Gago, Vanesa Maja. Matías López Stordeur (voz en off)

\section{Nuestro teatro - Obras premiadas}

"Civilización, escrita por Mariano Nicolás Saba (CABA).

»La pasión según Teresa Von Hauptbanhof, escrita por Cristian Palacios (Villa Bosch, Bs. As.).

"El ojo del destino, escrita por Francisco Estrada (Vicente López, Bs. As.).

"Asteroide, escrita por María Zubiri (CABA).

"Al hueso, escrita por Santiago Dejesus (Rosario, Santa Fe).

"El presente de Eduardo, escrita por Juan Felipe Villanueva (CABA).

»Puzzle, escrita por Sergio Omar Lupardo (Villa Lynch, Bs. As.).

»Amarga Marietta, escrita por Patricia Suárez (CABA).

"Lo sutil del desamor, escrita por Anahí Ribeiro (CABA).

»Esa iglesia llena de enemigos armados hasta los dientes, escrita por Agustín Sáiz (Mar del Plata, Bs. As.).

"Esto no es una emergencia, escrita por Nancy Lago (CABA).

"Un Hembro, escrita por Rubén Sabadini (CABA).

"Al oeste del amor, escrita por María Figueras (CABA). 
»Blizzard, escrita por David Angel Gudiño (CABA).

» La ilusión del Rubio, escrita por Santiago San Paulo (Córdoba, Córdoba).

"Hipólita pondera la conquista, escrita por Eric Barenboim (CABA).

»Camarín 19, escrita por Vera Czemerinski (CABA).

"La imprenta, escrita por Gabriel Patricio Graves e Isod (CABA).

"El rumor de las palomas, escrita por Mario Costello (Tucumán, Tucumán).

"El derecho de las cosas, escrita por Guillermo Arengo (CABA).

»Once Berlín, escrita por Florencia Carosía (CABA). 